\title{
TRADUÇÃO OU ADAPTAÇÃO? UMA ANÁLISE DA VERSÃO DO POEMA “O CORVO” PARA OS QUADRINHOS
}

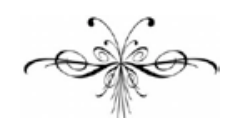

\author{
Juliana Mendes De Oliveira
}

Resumo: O estudo do conceito e do processo de adaptação tem sido uma preocupação frequente tanto nos Estudos de Tradução quanto em sua disciplina correlata e ainda recente: os Estudos de Adaptação. A fim de contribuir com essa discussão, o presente artigo tem como proposta principal a elaboração de uma breve descrição e análise da versão brasileira para os quadrinhos do poema “The Raven” de Edgar Allan Poe, feita a partir da tradução de Machado de Assis. Com base em algumas passagens dos quadrinhos, discutimos os conceitos de tradução e adaptação, bem como a fronteira entre ambos os termos, e também o conceito de tradução intersemiótica. Com tal intuito, utilizamos como apoio teórico algumas reflexões de Jakobson (1971), Plaza (2001) Amorim (2005), Venuti (2007) e Milton (2010). Além de uma análise sobre um tipo ainda pouco frequente de adaptação (literatura para os quadrinhos), espera-se obter como resultados generalizações teóricas que ampliem a reflexão acerca dos conceitos de tradução e adaptação aplicados a um exemplo concreto dessas operações de linguagem.

Palavras-chave: Estudos da Tradução; Estudos de Adaptação; Linguística Aplicada; Literatura Americana; Histórias em Quadrinhos.

\begin{abstract}
The study on the adaptation concept and process has been frequently a concern on Translation Studies as well as on its correlate and young discipline, Adaptation Studies. In order to contribute to this discussion, this essay mainly attempts to elaborate a brief description and analysis on the Brazilian version for a comic book of the poem The Raven by Edgar Allan Poe, based on Machado de Assis' translation. Based on some passages of the comic book, we discuss translation and adaptation concepts, as well as the boundary between them, and we also discuss the concept of intersemiotic translation. With that in mind, we use as theoretical support some reflections from Jakobson (1971), Plaza (2001) Amorim (2005), Venuti (2007) and Milton (2010). Besides providing an analysis about a not very often kind of adaptation (literature text into a comic book), the expected results are theoretical generalizations which may amplify reflections towards the concepts of translation and adaptation applied to a concrete example of these language operations.
\end{abstract}

Keywords: $\quad$ Translation $\quad$ Studies; Adaptation Studies; Applied Linguistics; American Literature; Comic Books. 


\title{
área de Estudos de Tradução tem se interessado pelo estudo do 1 momento parece difícil de definir e delimitar, tem sido de fato
} utilizado de forma bastante ampla, em alguns casos sendo considerado como um processo que engloba a tradução (Amorim, 2005). Segundo Venuti (2007), processo de tradução difere do processo de adaptação da seguinte forma:

\begin{abstract}
An adaptation, in contrast, might depart widely from its prior materials, submitting them to various kinds of manipulation and revision. Nonetheless, a translation can never simply communicate in whole or in part the text that it translates; it can only inscribe an interpretation that inevitably varies the form and meaning of that text. Translation can be regarded as intercultural communication only if we recognize that it communicates one interpretation among other possibilities. ${ }^{1}$
\end{abstract}

Verificamos que Venuti (2007) vê a tradução como um processo que não resgata plenamente o texto original, sendo apenas uma entre as muitas interpretações possíveis daquele texto. Já a adaptação, aparentemente se afasta mais de seu material inicial e envolve vários tipos de manipulação e revisão. Assim sendo, a adaptação parece ser um processo mais livre e manipulativo se comparado com a tradução.

De forma geral, os tipos de adaptação mais frequentes e até em virtude deste fato, os que causam mais interesse dos estudiosos da área são: adaptação de literatura para o cinema, de literatura para o teatro e do teatro para o cinema. De tal modo, os recentes Estudos de Adaptação, bem como os Estudos de Tradução se debruçaram mais frequentemente sobre a tríade Literatura/Cinema/Teatro do que sobre qualquer outro tipo de mídia. Tendo em vista tal fato, a proposta deste trabalho consiste na descrição e breve análise de um gênero de adaptação ainda não muito explorado do ponto de vista acadêmico até o presente momento: adaptação de literatura para história em quadrinhos.

O objetivo deste trabalho é apresentar e analisar brevemente a adaptação do célebre poema "O Corvo" ("The Raven”) de Edgar Allan Poe, adaptado para os quadrinhos a partir da tradução de Machado de Assis para o português brasileiro. Para este fim, serão utilizados os pressupostos teórico-metodológicos acerca dos conceitos de tradução e adaptação de Milton (2010) e Amorim (2005), bem como o conceito de tradução intersemiótica conforme exposto por Jakobson (1971) e Plaza (2001).

\section{Sinopse do poema adaptado}

O poema "O Corvo" (“The Raven”), do escritor norte-americano Edgar Allan Poe (1809-1849) ganhou nova versão em HQ no ano de 2009, ano em que se completaram 200 anos do nascimento do autor. Foi publicado pela primeira vez em 1845, já na maturidade de Poe e próximo de sua morte precoce, aos quarenta anos de idade. O poema, muito admirado pela linguagem musical e pelo conteúdo metafísico, recebeu traduções de grandes expoentes da literatura, tais como Baudelaire, Mallarmé, Fernando Pessoa e Machado de Assis. (Ver capa na figura 1).

\footnotetext{
${ }^{1}$ VENUTI, Lawrence. Adaptation, Translation, Critique. Journal of Visual Culture 6; 25. SAGE Publications: Los Angeles, London, New Delhi and Singapore, 2007.
} 


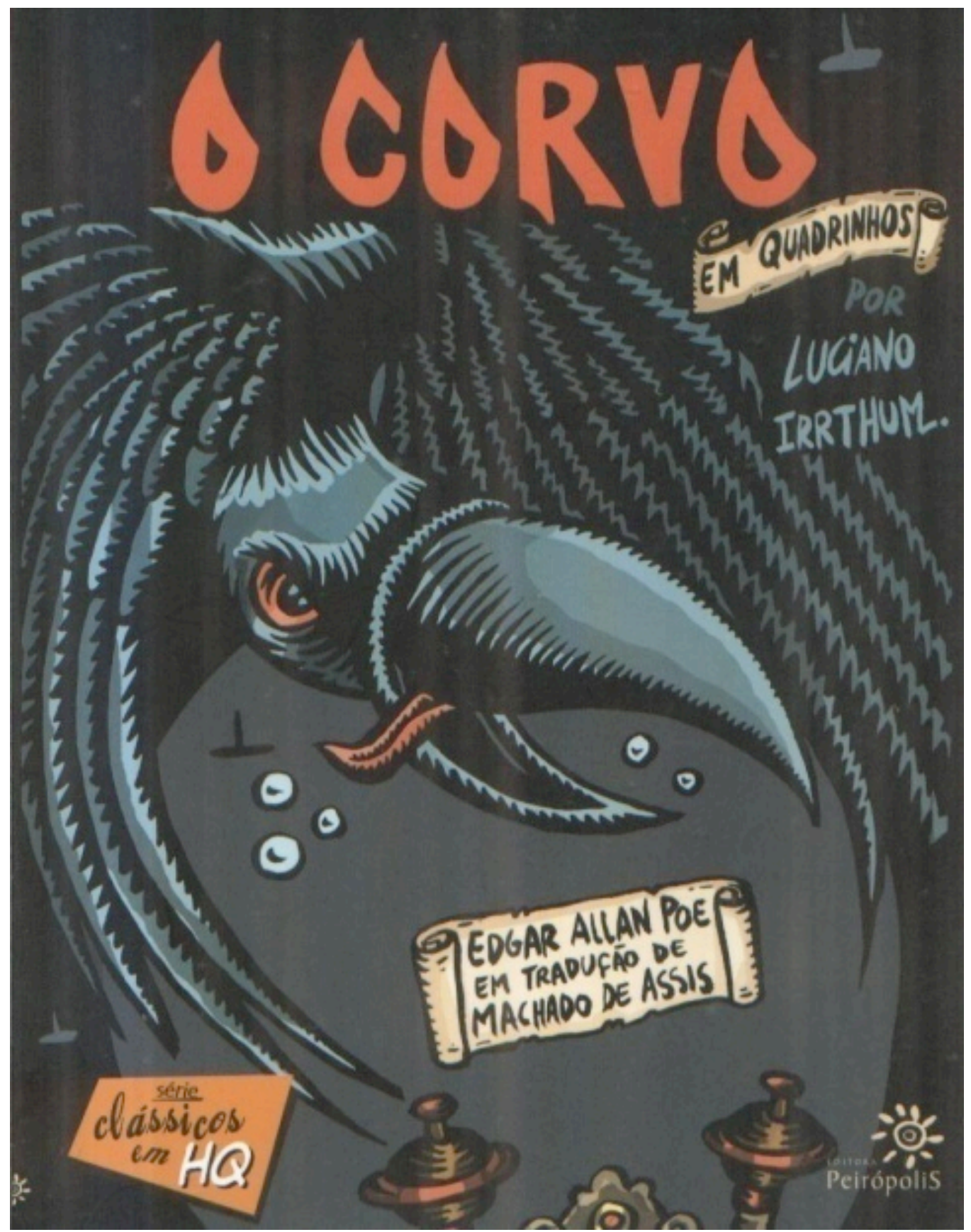

Figura 1 - Capa de O Corvo em Quadrinhos

Nesta versão da coleção “Clássico em Quadrinhos” da Editora Peirópolis, conforme se pode ler na contracapa da publicação, "O Corvo renasce das mãos do quadrinista Luciano Irrthum, que expressa sua reverência pela obra imprimindo-lhe o lirismo, a força e a visceralidade de seu traço”.

\section{Sinopse do autor da adaptação}

Luciano Irrthum nasceu em 3 de junho de 1972 em João Monlevade (MG), e vive em Belo Horizonte. Formado em design gráfico pela Fuma (Fundação Mineira de 
Arte Aleijadinho) - UEMG, localizada em Belo Horizonte. É ilustrador, quadrinista e artista plástico. Publica seus quadrinhos e desenhos em revistas independentes, como Graffiti 76 por cento Quadrinhos, Legenda e Front. Participou de várias exposições coletivas no Brasil e no exterior. É autor de A comadre do Zé, da Graffiti, e de $O$ corvo em quadrinhos, da coleção "Clássicos em Quadrinhos" da Editora Peirópolis. O website do quadrinista pode ser conferido no endereço: http://www.irrthum.com/. É possível adquirir O Corvo em Quadrinhos ou conhecer todo o catálogo da Editora Peirópolis, navegando no site da editora: http://www.editorapeiropolis.com.br/.

\section{Explorando O Corvo em Quadrinhos}

Quando se fala em adaptações de textos literários, seja para o cinema, teatro ou outro gênero, nossa tendência natural é pensar que se trata de um texto em prosa, como um conto ou um romance. No caso aqui em tela, no entanto, trata-se da adaptação de um poema, o que não é muito comum. O que faz então, com que o este poema de Edgar Allan Poe seja adaptável? O elemento fundamental que permite que o poema "O Corvo" tenha sido adaptado para os quadrinhos é o fato de que se trata de um poema narrativo, o qual, portanto relata uma sequência de fatos com começo, meio e fim, o que faz com que se encaixe facilmente na estrutura dos quadrinhos. Assim sendo, foi perfeitamente possível ao quadrinista transferir a estrutura narrativa do poema para a estrutura narrativa de uma história em quadrinhos. (Ver figura 2).

Dito isso, vamos começar pela descrição e análise da abertura do livro:
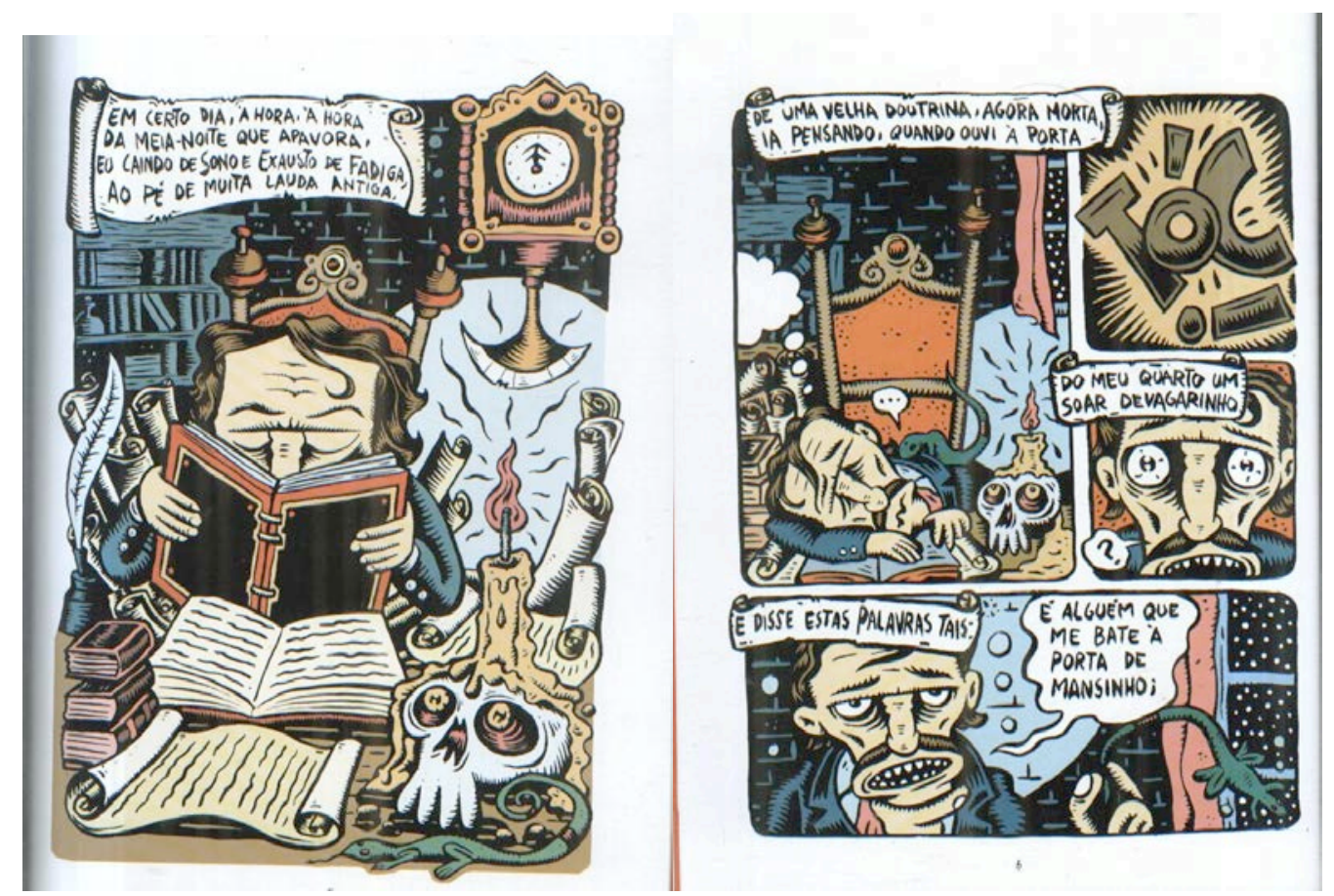

Figura 2 - Abertura de O Corvo em Quadrinhos

Conforme já foi dito anteriormente, essa adaptação do poema de Edgar Allan Poe para os quadrinhos não foi feita com base no poema original em inglês, mas sim com base na tradução para o português de Machado de Assis. É, portanto, uma tradução/adaptação feita para o público brasileiro, de forma que os elementos do poema ganham forma e cor nos quadrinhos de acordo com a releitura e recriação que Machado de Assis produziu a partir do poema original. Ainda assim, veremos que o 
quadrinista não deixou em nenhum momento de procurar resgatar o estilo e a atmosfera de Poe quando recriou as cenas a partir do seu traço. Ele procurou recriar toda a atmosfera sombria do texto de Poe, bem como o tempo e o espaço expressos no poema, como por exemplo, o relógio na parede que marca meia-noite, a expressão constante de angústia no rosto do personagem principal, e a sua mesa cheia de livros, no meio dos quais o personagem adormece. Note-se ainda que na história em quadrinhos, consta o texto da tradução de Machado na íntegra ${ }^{2}$, com um ou mais trechos em cada quadro, de acordo com o critério de divisão estabelecido pelo quadrinista.

Notam-se alguns elementos interessantes no caso dessa adaptação, como por exemplo, o desenho do gato preto na figura abaixo, que não está presente no poema original de Poe, nem na tradução de Machado. Vemos que o quadrinista exerceu aqui sua autoria sobre o original e sua tradução, ao optar por inserir um elemento de intertextualidade com outro texto escrito por Poe, no caso em questão o conto The Black Cat. (Ver figura 3).

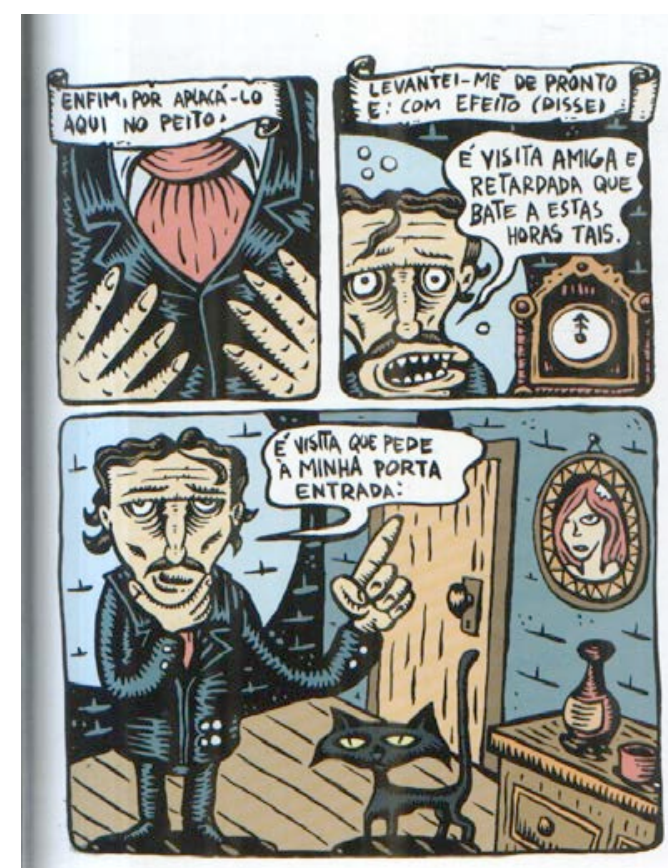

Figura 3 - intertextualidade com o conto The Black Cat.

Ainda observando a Figura 3, podemos notar outro elemento de intertextualidade bastante patente, quando observamos as feições físicas do personagem principal dos quadrinhos. Trata-se do rosto do próprio Edgar Allan Poe, que na releitura do quadrinista, não é apenas o escritor, mas o próprio personagem da narrativa do poema.

\footnotetext{
${ }^{2}$ A escolha do quadrinista pela tradução de Machado de Assis, entre tantas traduções existentes do poema para o português, conforme o encarte da publicação, é justificada pelo fato de que o ano de 2009, ano da publicação de O Corvo em Quadrinhos, foi o ano do bicentenário de Poe e também do centenário da morte do escritor brasileiro, além do fato de Poe ter sido um dos escritores favoritos de Machado.
} 


\section{Tradução e Adaptação}

No que concerne aos conceitos de tradução e adaptação, Milton (2010) enumera alguns dos termos frequentemente encontrados na área de Translation Studies e Adaptation Studies para a definição de adaptação.

(...) a number of the terms used in the area, many of which are selfexplanatory, may be mentioned: adaptation, appropriation, recontextualization, tradaptation, spinoff, reduction, simplification, condensation, abridgement, special version, reworking, offshoot, transformation, remediation, re-vision. ${ }^{3}$

Certamente, muitas das definições acima podem ser utilizadas no caso da adaptação aqui em análise, porém, dadas as características da obra, podemos classificar o caso em questão como tradaptation, special version e reworking. Não são certamente as únicas definições que servem, mas certamente são as que mais se aplicam, uma vez que se trata da adaptação de uma tradução (tradaptation), de uma versão especial do poema vertido para os quadrinhos (special version), e de um reelaboração do poema traduzido no formato de quadrinhos (reworking).

Amorim (2005), ao abordar os conceitos de tradução e adaptação, afirma que embora operem em níveis semelhantes, o grau e a natureza da aplicação mental varia a cada caso. Ainda segundo Amorim (2005), a adaptação é um processo mais extensivo e frequentemente engloba a tradução. Esta do autor descreve bem o processo de recriação utilizado no caso da adaptação de "O Corvo" para os quadrinhos, pois trata-se especificamente de uma adaptação que foi concebida não a partir do texto original de Poe, mas sim a partir da tradução de Machado de Assis ${ }^{4}$. É, portanto a adaptação de uma tradução, ou seja, uma tradaptação, em que o quadrinista acaba também por exercer a função de segundo tradutor do texto original, no momento em que o transforma em outra mídia.

Também segundo Amorim, “a adaptação por um lado seria mais flexível por permitir maior espaço para modificações ou 'perda de informação'. A tradução, por outro, reproduziria a totalidade da informação, exigindo maior rigor e fidelidade ao original." ${ }^{5}$ De fato, notamos que há diversos elementos que foram modificados ou adicionados pelo quadrinista em sua adaptação, como por exemplo, a já citada inserção do desenho do gato preto, que dialoga com a obra de Poe, embora não esteja presente no poema original. Na Figura 2, o quadrinista desenha um crânio, que serve como castiçal de uma vela em cima da mesa. Essa imagem também não está presente no texto original de Poe, nem na tradução de Machado, sendo assim um elemento de criação do quadrinista (possivelmente inspirado em Hamlet de Shakespeare) no intuito de dar forma à atmosfera sombria de Edgar Allan Poe.

\footnotetext{
3 MILTON, John. Adaptation In: Handbook of Translation Studies. John Benjamins Publishing Company, 2010.

${ }^{4}$ Textualmente falando, os desenhos seguiram a tradução de Machado, contudo, o autor leu o texto original, conforme texto do posfácio da publicação, em que o quadrinista afirma que quando conheceu os escritos de Poe no livro que ganhou de seu avô, ele ficou muito impressionado com seus contos e poemas. Portanto, embora os desenhos sejam essencialmente recriações do texto de Machado, por certo há também elementos da atmosfera noturna e sombria do texto original de Poe.

${ }^{5}$ AMORIM, Lauro Maia. Tradução e Adaptação. Encruzilhadas da Textualidade em Alice no País das Maravilhas de Lewis Carrol, e Kim, de Rudyard Kipling. São Paulo: Editora UNESP, 2005.
} 
A fim de elucidar como se deu este processo de adaptação, consideremos a Figura 3 e posteriormente a Figura 4, que mostram a entrada do corvo na casa do personagem principal:
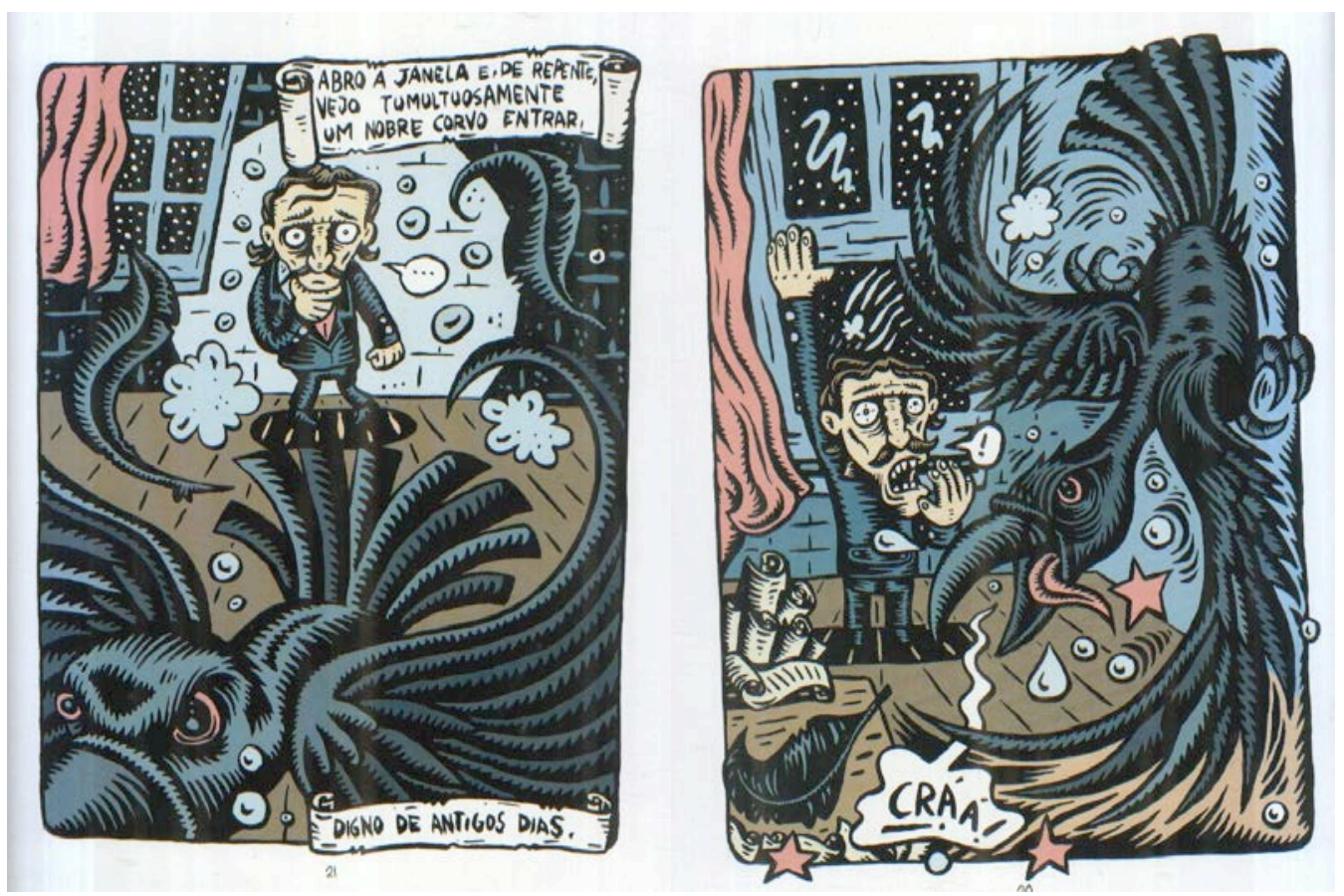

Figura 3 - A entrada do corvo

Podemos ver na figura 3, que o quadrinista procurou expressar na mesma sequência de fatos, o que diz a tradução de Machado. O texto diz:

\section{Abro a janela e de repente \\ Vejo tumultuosamente \\ Um nobre corvo entrar \\ Digno de antigos dias}

Ao compararmos o texto com as figuras, constatamos que o quadrinista teve a preocupação de retratar todo o tumulto que o corvo fez ao entrar.

Consideremos agora o texto disponível na Figura 4 abaixo:

Não despendeu em cortesias

Um minuto, um instante. Tinha o aspecto

de um lord ou de uma lady. E pronto e reto,

Movendo no ar as suas negras alas,

Acima voa dos portais,

Trepa, no alto da porta em um busto de Palas:

Trepado fica, e nada mais. 

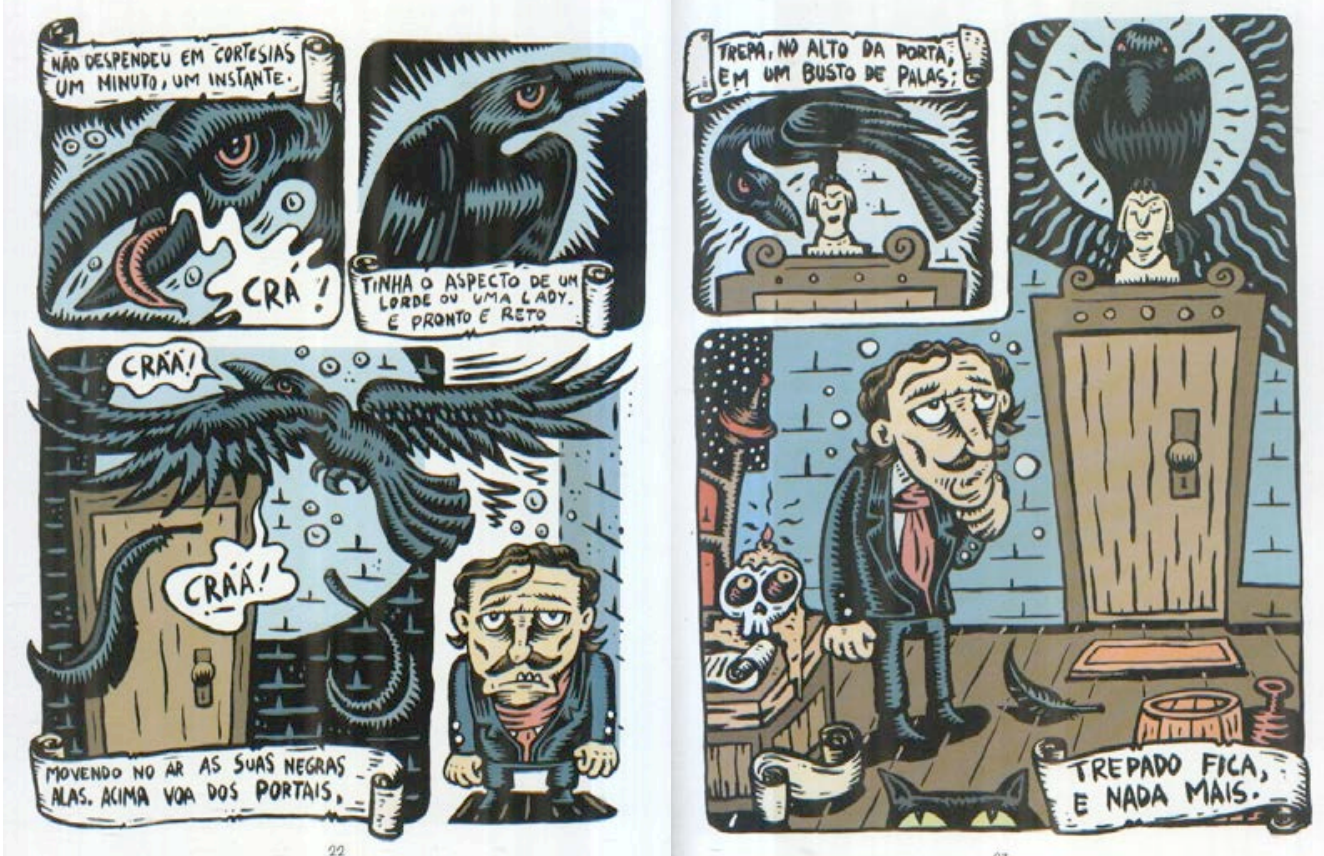

Figura 4 - a entrada do corvo (continuação)

Nota-se que o quadrinista recriou com precisão em seus quadrinhos toda a sequência narrada no poema. Contudo, o aspecto de nobreza do corvo que é descrito neste trecho não parece estar presente nos desenhos. O traço dado ao corvo, em certa medida, contrasta com a tradução comedida de Machado, dando a impressão de que o quadrinista ironiza a tradução em alguns momentos.

\section{Tradução intersemiótica}

Um dos conceitos que também podemos atribuir à adaptação feita de um poema para os quadrinhos é o de tradução intersemiótica.

Jakobson $(1971)^{6}$, ao abordar os aspectos linguísticos da tradução, definiu a tradução intersemiótica como transmutação de signos, de um sistema semiótico em outro sistema, de diferente natureza, ou seja, é um processo que consiste na interpretação de signos textuais por outros signos não-verbais. Jakobson diz ainda que a tradução intersemiótica "envolve mensagens equivalentes em códigos diferentes". No caso em tela, o sistema de signos "poema" foi transmutado ou recriado para o sistema de signos "história em quadrinhos".

Embora Jakobson tenha sido o criador do conceito de tradução intersemiótica, foi Plaza (2001) quem, a partir do termo cunhado por Jakobson, dedicou um livro inteiro voltado para a tradução intersemiótica, livro este que foi dedicado às artes. Baseado na semiótica de Pierce, Plaza (2001) propõe três categorias de tradução intersemiótica: ${ }^{7}$

\footnotetext{
${ }^{6}$ JAKOBSON, Roman. Lingüística e comunicação. São Paulo: Cultrix, 1971.

${ }^{7}$ PLAZA, Julio. Tradução Intersemiótica. São Paulo: Perspectiva, 2001.
} 
- Tradução icônica: feita pela semelhança de estrutura, onde se pode configurar diferentes elementos em sistemas similares ou elementos similares em sistemas diferentes.

- Tradução indicial: feita pelo contato, ou presença do original na tradução, por proximidade. O original inteiro é trazido para um novo meio, que promove uma ressemantização do referente, ainda que mantenha uma relação pontual entre os elementos dos dois conjuntos (original e tradução).

- Tradução simbólica: busca a proximidade de referências convencionais através de metáforas e símbolos; em outras palavras, busca apontar para as mesmas referências do original, o que pressupõe um conhecimento prévio destas referências.

De acordo com a classificação acima, podemos afirmar que essa tradução/adaptação do poema “O Corvo” para os quadrinhos é, a um só tempo, uma tradução indicial e uma tradução simbólica. Trata-se de uma tradução indicial, pois o original inteiro, no caso, o poema de Poe traduzido por Machado de Assis, foi levado para um novo meio, um novo gênero, no caso, a história em quadrinhos, havendo assim uma ressemantização do referente, causada pela própria mudança de suporte e de gênero, e também pela releitura do texto verbal que foi feita a partir do olhar do quadrinista. É também uma tradução simbólica, pois há uma enorme presença de metáforas e símbolos do original, elementos estes que foram resgatados na adaptação, como por exemplo, o relógio na parede marcando meia-noite e os livros espalhados em cima da mesa do personagem principal, conforme notamos na Figura 2.

Embora essa adaptação do poema para os quadrinhos configure como um todo uma tradução intersemiótica, em alguns trechos, este processo fica mais evidente. Consideremos a Figura 5 abaixo:
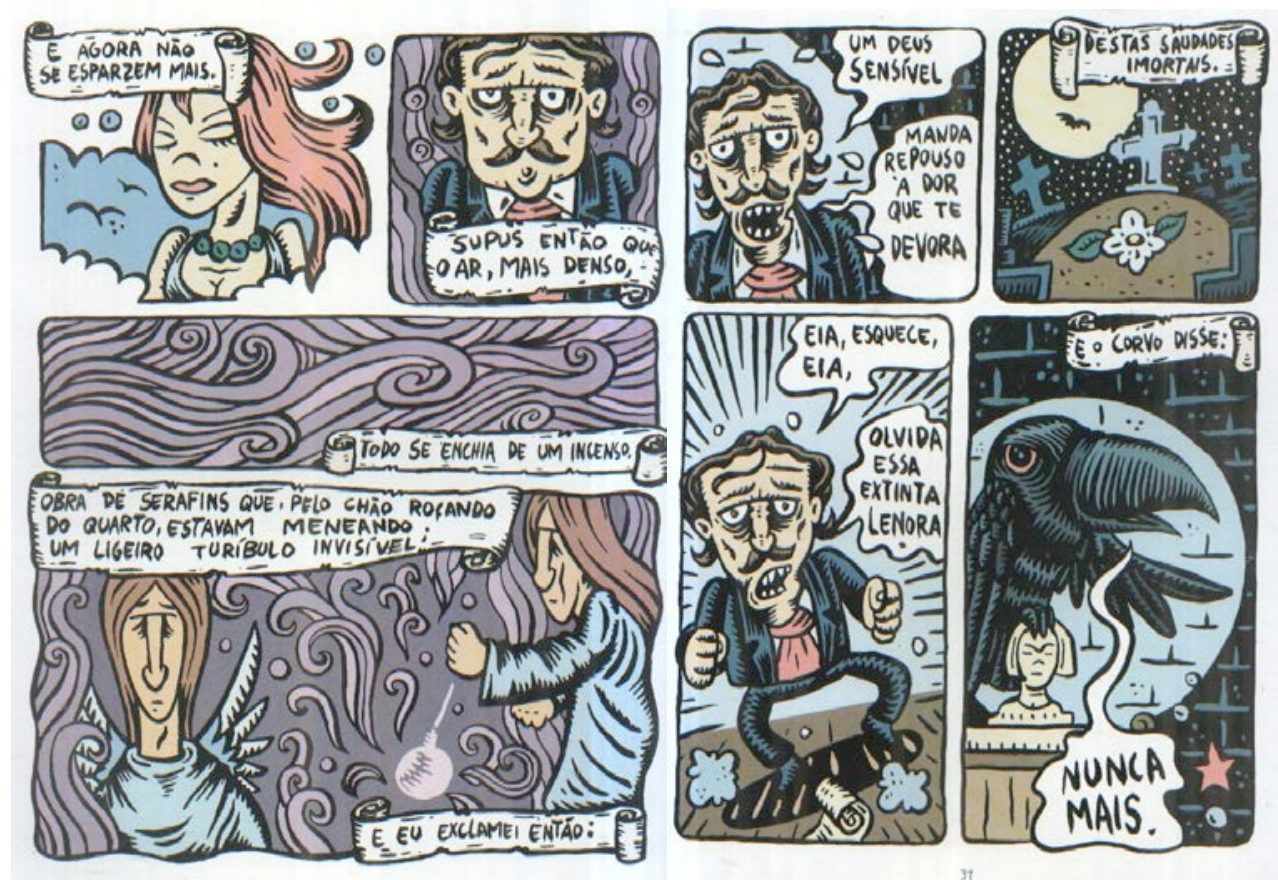

Figura 5 - Elementos de Tradução Intersemiótica

Na primeira parte da Figura 4, diz o texto do poema: 
Supus então que o ar, mais denso,

Todo se enchia de um incenso,

Obra de serafins que, pelo chão roçando

Do quarto, estavam meneando

Um ligeiro turíbulo invisível:

Nota-se que a sequência dos quadrinhos retrata ricamente essa sensação do personagem principal de sentir o ar mais denso, com cheiro de incenso, que saía do turíbulo de serafins. Não é de fato uma cena da narrativa do poema, pois trata-se apenas de uma sensação do personagem à qual o quadrinista deu vida com riqueza de detalhes.

Consideremos agora a Figura 6:
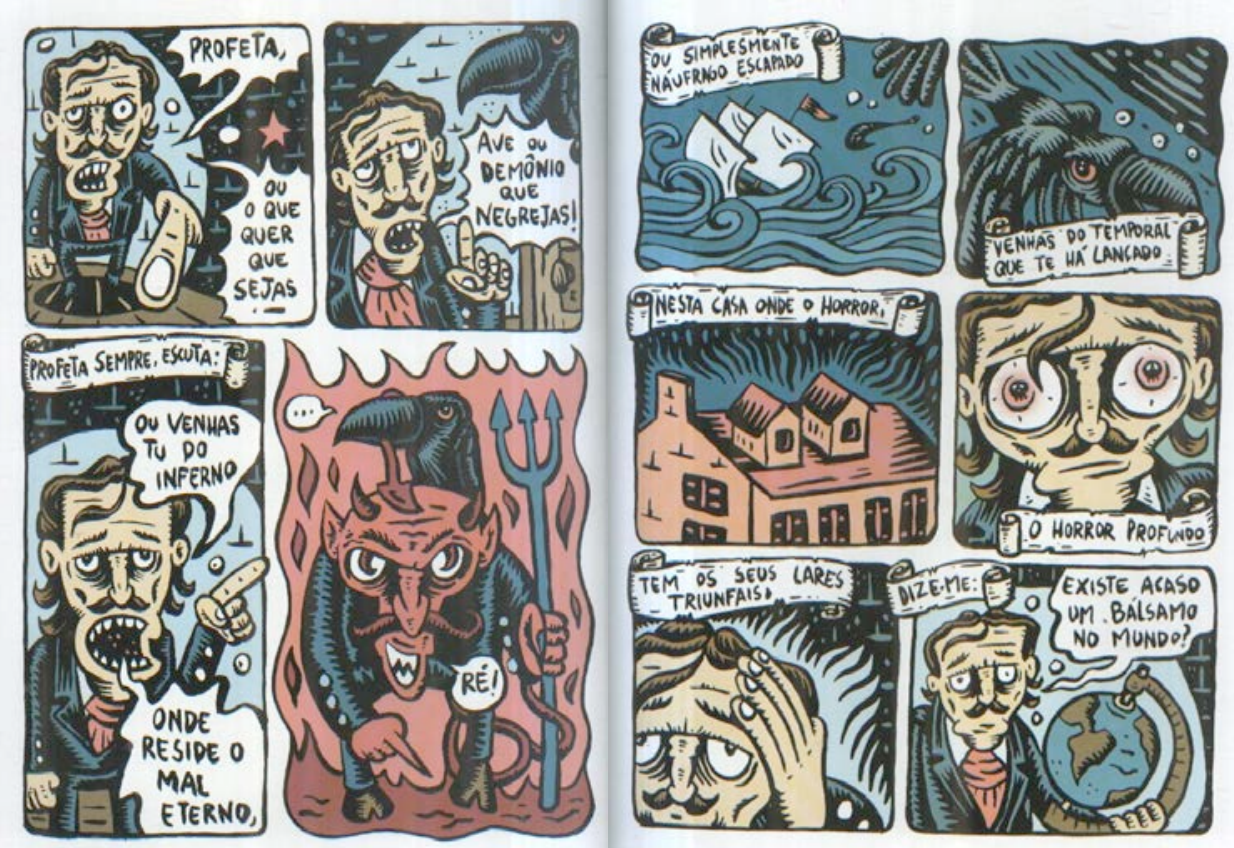

Figura 6 - Elementos de Tradução Intersemiótica

Na Figura 6, diz o texto do poema:

Profeta, ou o que quer que sejas!

"Ave ou demônio que negrejas!

"Profeta sempre, escuta: Ou venhas tu do inferno

"Onde reside o mal eterno,

"Ou simplesmente náufrago escapado

"Venhas do temporal que te há lançado

"Nesta casa onde o Horror, o Horror profundo

"Tem os seus lares triunfais,

"Dize-me: existe acaso um bálsamo no mundo?"

Observando a Figura 6, vemos que o quadrinista deu forma e contorno a todas as idéias e sentimentos expressos pelo personagem principal, como o inferno, em que retratou inclusive o próprio diabo, o náufrago, a casa e a sensação de horror profundo. Interessante notar que quando ele diz "bálsamo no mundo”, o personagem foi retratado literalmente segurando o mundo nas mãos. 
Sendo assim, uma leitura possível é que a adaptação feita pelo quadrinista resultou em uma tradução intersemiótica, pois ele transmutou e recriou as suas impressões do texto verbal, convertendo-o em texto não-verbal, transformando signos do texto escrito em signos imagéticos, os quais por vezes mostram-se bastante explicativos, de maneira que em alguns casos, a transmutação de signos chega a ser feita praticamente ao pé da letra.

Os Estudos da Tradução e os recentes Estudos da Adaptação têm frequentemente se interessado por adaptações da literatura para o teatro, literatura para o cinema e teatro para o cinema, em que os textos literários adaptados normalmente são em prosa. O presente artigo teve como objetivo discutir os conceitos de tradução, adaptação e tradução intersemiótica a partir da breve descrição e análise de um tipo de adaptação ainda pouco frequente e consequentemente pouco explorado: a adaptação do texto literário para história em quadrinhos, neste caso, o poema "The Raven” de Edgar Allan Poe, adaptado para os quadrinhos pelo quadrinista Luciano Irrthum, adaptação feita com base na tradução do poema para o português de Machado de Assis, configurando, portanto uma "tradaptação". O poema "The Raven”, embora não seja um texto em prosa, é adaptável devido à sua estrutura narrativa, que pode facilmente ser convertida na estrutura narrativa de um filme, uma peça teatral ou uma história em quadrinhos. Vimos que este processo de adaptação que converte signos verbais em signos não-verbais pode também ser compreendido como uma tradução intersemiótica, de modo que na adaptação aqui analisada, o texto foi transformado em imagens, muitas vezes literalmente. Em outros casos, o quadrinista, o qual pode-se dizer que atuou como o segundo tradutor do texto original de Poe, deixou traços de sua autoria, quando, por exemplo, incorporou em seus quadrinhos elementos de intertextualidade com outros textos de Poe, ou ainda quando adicionou elementos não claramente presentes no texto original ou na tradução de Machado de Assis.

Juliana Mendes de Oliveira julimendes_usp@yahoo.com.br Universidade de São Paulo

\section{Referências}

AMORIM, Lauro Maia. Tradução e Adaptação. Encruzilhadas da Textualidade em Alice no País das Maravilhas de Lewis Carrol, e Kim, de Rudyard Kipling. São Paulo: Editora UNESP, 2005.

IRRTHUM, Luciano. O Corvo em Quadrinhos. Texto de Edgar Allan Poe. Tradução de Machado de Assis. São Paulo: Peirópolis, 2009.

JAKOBSON, Roman. Lingüística e comunicação. Tradução de Izidoro Blikstein e José Paulo Paes. São Paulo: Cultrix, 1971.

MILTON, John. “Adaptation”. In: Handbook of Translation Studies. Amsterdam/Philadelphia: John Benjamins, 2010.

PLAZA, Julio. Tradução Intersemiótica. São Paulo: Perspectiva, 2001.

VENUTI, Lawrence. Adaptation, Translation, Critique. Journal of Visual Culture 6; 25. SAGE Publications: Los Angeles, London, New Delhi and Singapore, 2007. 